\title{
Tabela Periódica com Realidade Aumentada Aplicada no Processo de Ensino e Aprendizagem de Química
}

\author{
Guilherme B. Guimarães ${ }^{1}$, Adilmar C. Dantas ${ }^{1}$, Emanuel V. M. Prates ${ }^{1}$, \\ Brenda O. Pereira ${ }^{1}$, Michel S. Xavier ${ }^{1}$, Eduardo K. Takahashi ${ }^{1}$ \\ ${ }^{1}$ Universidade Federal de Uberlândia (UFU) \\ Uberlândia - MG - Brazil \\ \{gui.brilhante, emanuelvitor-vixe\}@outlook.com, \\ \{akanehar, brendinha.op01, ektakahashi\}@gmail.com
}

\begin{abstract}
On this paper, a new Augmented Reality (AR) app applied to the chemistry subject, for teching the elements of the periodic table is presented. In the app, besides the possibility of visualizing the elements threedimensionaly, information, features and specific applications of each element are presented. The developed app is available for free for mobile Android devices and has over 100 active users. Hereafter, it is intended to effect the application along public high school institutions to evaluate the contribution degree of these technologies in the scholar environment.
\end{abstract}

Resumo. Este trabalho tem como objetivo apresentar um aplicativo com Realidade Aumentada (RA) aplicado na disciplina de química, referente ao ensino dos elementos químicos presentes na tabela periódica. No aplicativo, além da possibilidade da visualização dos elementos desenvolvidos tridimensionalmente $(3 D)$ é disponibilizado também as informações, características e aplicações particulares de cada elemento. $O$ aplicativo desenvolvido está disponivel gratuitamente para aparelhos móveis com sistema Android e possui mais de 100 usuários ativos. Futuramente pretende-se efetuar a aplicação junto a instituições públicas de Ensino Médio para avaliar o grau de contribuição dessas tecnologias no ambiente escolar.

\section{Introdução}

O constante avanço tecnológico nas ultimas décadas proporcionou diversas oportunidades para a utilização da tecnologia junto à educação. Atualmente grande parte dos estudantes dispõem no mínimo de algum aparelho tecnológico e cabe aos educadores encontrar e elaborar metodologias para a utilização desses aparelhos, que estão cada vez mais presente no cotidiano dos estudantes, como celulares, tablets ou computadores. Tais tecnologias quando aplicadas no contexto educacional, se tornam motivadoras e fazem com que os estudantes se envolvam mais no processo de aprendizagem.[Herpich et al. 2017].

A Realidade Aumentada (RA) permite aos estudantes elaborarem uma nova concepção de mundo, em que se projeta os objetos bidimensionais (2D) e tridimensionais (3D) no mundo real, ela se trata de uma inclusão de sobreposições gráficas na realidade. [Azuma 1997] Ocasionalmente, a RA torna-se uma complementação da realidade, dando a impressão da coexistência dos objetos reais com os virtuais que ficam fixados no espaço em determinadas localizações. [Billinghurst 2002] 
De acordo com [Billinghurst 2002] no contexto educacional destacam-se fatores positivos observados com utilização da RA, sendo eles:

- RA possibilita o trabalho contínuo, interagindo entre o ambiente real e virtual;

- A utilização de interfaces que viabilizam a manipulação de objetos;

- A inserção tecnológica para uma transição suave entre o mundo real e o virtual.

A RA demonstra dispor de grande potencial para uso educacional pois permite explorar conceitos abstratos nas áreas de ciências, elaboração de novas metodologias, implementação de tecnologias na educação e é um possível potencializador para o aprendizado dos estudantes. Esse trabalho consiste no desenvolvimento de um aplicativo acessível em realidade aumentada, denominado "Elements - Tabela Periódica" com o objetivo de auxiliar os estudantes no processo de aprendizagem dos elementos da tabela periódica de maneira interativa.

\section{Desenvolvimento do software}

Para o desenvolvimento do aplicativo foi utilizado um Kit de Desenvolvimento de Software, do inglês Software Development Kit (SDK) para RA, denominado Vuforia, ela utiliza recursos de visão computacional avançada para desenvolver facilmente aplicativos para plataformas Android, IOS, UWP, permitindo unir mundos reais e virtuais [Vuforia 2018], ela foi utilizada em conjunto com o software multiplataforma de motor gráfico Unity3D, um poderoso software livre que apresenta uma enorme gama de recursos, além de permitir também a realização de animações, programação avançada, desenvolvimento mobile, web.

Para o desenvolvimento dos elementos utilizou-se de fontes confiáveis, pois era necessário o uso de imagens e vídeos que demonstrassem os elementos em seu estado puro e suas devidas aplicações. Esse material foi extraido da obra The Elements: A Visual Exploration of Every Known Atom in the Universe de Theodore Gray, disponibilizado gratuitamente através de um site $\rrbracket^{1}$ Esse trabalho serviu de base para a extração das características dos elementos químicos presentes no aplicativo.

Os modelos tridimensionais dos elementos químicos foram elaborados utilizando dois softwares gratuitos. O SketchUp, um software de modelagem 3D simples e com diversas funcionalidades, utilizado recorrentemente por arquitetos, designs e engenheiros devido às suas ferramentas que permitem transgredir de linhas e formas em 2D para objetos e modelos 3D [SketchUp 2018], foi utilizado também o Blender, um software de modelagem, com várias funcionalidades que permitem o desenvolvimento de modelagens complexas, manipulações, animações, renderizações e simulações diversas. [Blender 2018]

\section{Apresentação do software}

O “Elements - Tabela Periódica” é um aplicativo móvel desenvolvido para plataforma Android e elaborado em conjunto com estudantes do ensino médio com o objetivo de proporcionar uma nova visualização da tabela periódica e dos elementos químicos presentes nela. O aplicativo pode ser obtido na Play Store no seguinte endereço eletrônico: https://play.google.com/store/apps/details?id=com.UFU.Elements.

\footnotetext{
${ }^{1}$ Disponível em: http://periodictable.com/theelements/pages.html .Acesso em: 14 Abr. 2018.
} 
VII Congresso Brasileiro de Informática na Educação (CBIE 2018)

Anais dos Workshops do VII Congresso Brasileiro de Informática na Educação (WCBIE 2018)

O aplicativo pode ser dividido em duas etapas, a primeira apresentada na Figura 1 . que tem como objetivo apresentar as informações físico-química dos elementos, como por exemplo: propriedades atômicas e físicas, calor específico, eletronegatividade, condução elétrica e térmica, densidade, dureza, configuração eletrônica, entre outros. Selecionando a tabela periódica, o estudante encontrará uma listagem com os elementos químicos e ao acessar um determinado elemento o mesmo terá acesso às informações citadas em uma guia específica para cada elemento.

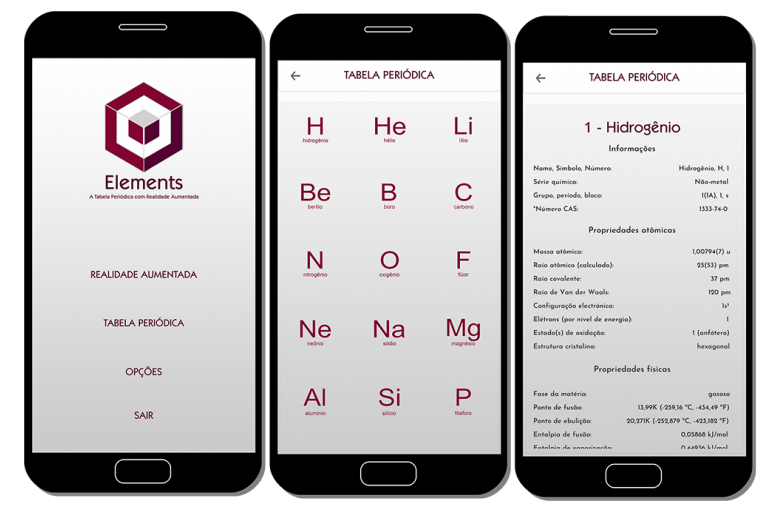

Figure 1. Interface principal do aplicativo e informações teórica dos elementos da tabela periódica

A segunda etapa se refere à Realidade Aumentada, que permite ao estudante visualizar os elementos químicos em 3D. Para acessar essa funcionalidade a câmera do celular precisa identificar a imagem ou marcador referente ao elemento químico, esses marcadores estão disponíveis no endereço localizado no rodapé desse trabalho². Na Figura 2 , é exibida a execução dessa funcionalidade no aplicativo, onde através dessa interface é disponibilizado para o estudante o elemento em formato 3D e sua respectiva descrição e características específicas.

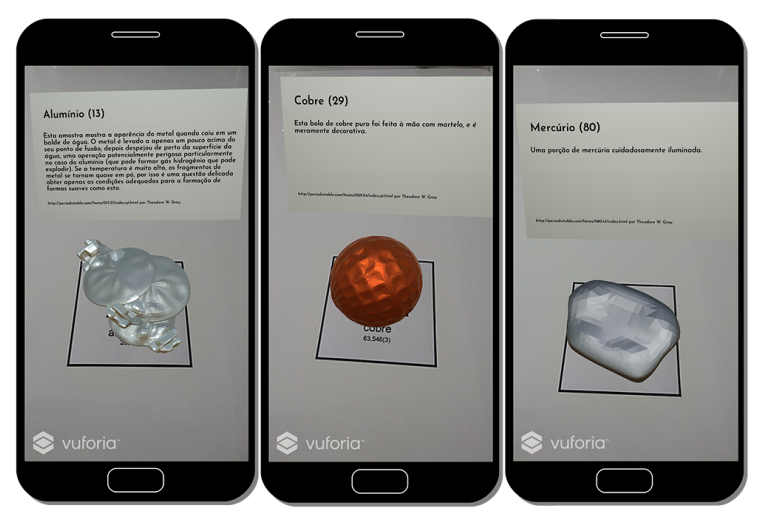

Figure 2. Visualização dos elementos químicos com Realidade Aumentada

\section{Considerações finais}

O desenvolvimento desse trabalho permitiu observar que a utilização de ferramentas tecnológicas, hoje cada vez mais presentes no cotidiano, em especial a Realidade Aumentada pode proporcionar no contexto educacional resultados significativos no processo

\footnotetext{
${ }^{2}$ Disponível em: https://mega.nz/\#F!GZ1CII6C!-FFPj6di958wip8T4QJcvw .Acesso em: 20 Mai. 2018.
} 
VII Congresso Brasileiro de Informática na Educação (CBIE 2018)

Anais dos Workshops do VII Congresso Brasileiro de Informática na Educação (WCBIE 2018)

de ensino e aprendizagem. Como trabalho futuro, pretende-se utilizar o aplicativo em uma instituição de ensino médio com o objetivo de verificar a real dimensionalidade das contribuições fornecidas pelo uso do aplicativo no contexto escolar. Atualmente a aplicação disponibilizada gratuitamente possui mais de 100 usuários com feedbacks positivos, além de contribuições que possibilitaram as atualizações constantes do aplicativo.

Apesar da limitação existente em que o aluno deve possuir um aparelho celular, a aplicação pode ser utilizada de forma colaborativa em grupos, contribuindo assim de maneira intensiva para o aprendizado em grupo dos alunos e consequentemente no crescimento do interesse pela disciplina, mesmo em situações onde essa limitação exista.

\section{References}

[Azuma 1997] Azuma, R. T. (1997). A survey of augmented reality. Presence: Teleoperators \& Virtual Environments, 6(4):355-385.

[Billinghurst 2002] Billinghurst, M. (2002). Augmented reality in education. New horizons for learning, 12(5).

[Blender 2018] Blender (2018). Blender about @ONLINE.

[Herpich et al. 2017] Herpich, F., Guarese, R. L. M., and Tarouco, L. M. R. (2017). Recursos de virtualidade integrados com realidade aumentada em dispositivos móveis para auxiliar estudantes na aprendizagem de física. In Anais dos Workshops do Congresso Brasileiro de Informática na Educação (CBIE), page 260.

[SketchUp 2018] SketchUp (2018). Sketchup @ONLINE.

[Vuforia 2018] Vuforia (2018). Vuforia developer library - getting started - ar features @ONLINE. 